Chapter 5

\title{
South Asian Students' Educational Experience and Attainment: Learning Chinese as a Second/Additional Language in Hong Kong
}

\section{Qunying Zhang, Linda Tsung, Ken Cruickshank,} Wing-Wah Ki and Mark Shiu-Kee Shum

\section{Introduction}

Hong Kong is a cosmopolitan city which is home to people from diverse origins. There are about 342,000 ethnic minority or mobile residents in Hong Kong, constituting $5 \%$ of the population. More than half of these people are originally from what are termed 'South Asian' (hereafter SA) countries including the Philippines, Indonesia, India, Nepal and Pakistan (Census and Statistics Department, 2007).

The SA communities traditionally relied on their home language and English (the prestige language in work contexts), but since the handover of sovereignty to China in 1997 , young people are faced with the need to gain high levels of fluency in Cantonese (the spoken language/dialect of the wider community) and literacy in Chinese to participate in the wider society. This chapter endeavours to explore the educational experiences and outcomes of minority students through the teaching of the Chinese language.

In the post-colonial context of an official shift to a trilingual (Cantonese, English and Putonghua) and biliterate (Chinese and English) society, education provision for ethnic minorities in Hong Kong has gained much more attention. Although the Hong Kong Special Administrative Region (HKSAR) Government policies over the past years have been committed to coexistence of multicultures and harmonious codevelopment of multiethnicities, the SA minorities are confronted with various difficulties in 
being integrated into Hong Kong society, especially in the fields of education and employment. Among the difficulties, the lack of sufficient Chinese language skills which lead to lower educational attainment seems to be salient (Ku et al., 2005, Loper, 2004, Tsung et al., 2008).

While the majority of SA background students attend government CMI (Chinese as the medium of instruction) schools where instruction is in Cantonese, there are also 16 primary and 9 secondary schools which are 'designated' for SA students. With targeted government grants and intensive school-based support, these designated schools are expected to address the issue of low school outcomes. Ethnic minority students mostly have English as the medium of instruction (EMI) and have Chinese as a subject taught generally using Cantonese whereas Chinese-speaking students in these schools are taught through Cantonese and are taught English as a subject. This means that minority students are streamed into classes different from local Chinese students. Some of these schools set intercultural understanding and social inclusion and harmony as substantial elements of their goals, but the actual degree of interaction between ethnic minority students and local Chinese students varies from school to school. The readiness and confidence of the Chinese teachers in teaching minority learners is also variable.

Many SA students in Hong Kong are unable to function in Chinese, or, even if they can speak Cantonese, their Chinese reading and writing skills are not good enough for them to receive CMI teaching. SA students enter the school system with fluency in their home language (Nepali, Urdu, Hindi, Punjabi) and generally some fluency in English. Some have levels of fluency in Cantonese but are faced with acquiring literacy in Chinese in the school system.

The majority of SA secondary students received primary education in Hong Kong (mostly from the designated primary schools), but there is also a significant portion of students (up to more than $20 \%$ in some schools) who are recent arrivals. Although most SA students have stronger English than Chinese, it does not necessarily mean that their English is fluent since there are constant new arrivals who are weak in both languages.

In order to meet university entrance requirement, SA students need to take a second language subject other than English. They generally did not take Chinese as the second language subject before 2007. Some took French, and others would take their heritage languages such as Hindi and Urdu, which are offered by a few of the schools. Most schools have become aware of the need of minority students to learn Chinese and hence provide them some tutorial lessons of Chinese in an attempt to improve their employment and tertiary education prospects. There is, however, no targeted external examination qualification for such learning. The Hong Kong Certificate of Education Examination (HKCEE) for Chinese subject, originally designed for local Chinese students, is not suited to the SA students as second/additional language learners. Therefore, Chinese language curricula for minority students in individual schools do not have clear definitions in terms of structure, progression and learning outcomes.

From 2007 government policy began to encourage SA students to take the General Certificate of Secondary Education (GCSE) Chinese examination as a goal. Some higher education institutions, as a response to the policy, began to accept Grade ' $D$ ' in the examination as their second language requirement for admission. It is assumed that this recognition can provide motivation for the students to learn Chinese, and also improve their chances of further study.

\section{Research into Educational Provision for Minority Students}

There is a strong research tradition from North America, United Kingdom, Europe and Australasia into minority background students and education which indicates that students from particular ethnic/language backgrounds have unsatisfactory educational experiences, outcomes which continue into second and subsequent generations. Global increases in migration since the 1950s have meant that issues to do with minority students and education have remained a research focus.

There have also been cross-national comparative studies of educational experiences and outcomes of minority groups (Crul and Vermeulen, 2003; PISA, 2004; 2006; Thomson and Crul, 2007). These studies have enabled comparisons of the same language/ethnic groups across national boundaries but being educated in similar contexts. There has been a shift from 'deficit' theories in the 1960s to models highlighting home/school 'discontinuities' and issues of social/cultural capital to a focus on the ways in which institutional and government policies are played out in school contexts (Portes and Rumbaut, 2001).

The most comprehensive study has been 'School Effectiveness for Language Minority Students' by Thomas and Collier (1997) in the United States. This study was based on a series of investigations of more than 700,000 students in 5 large school systems between 1982 and 1996. The researchers found 3 key predictors of academic success to be more important than any other set of variables such as socio-economic status or gender variables. The first 
predictor of long-term success is second language instruction through subject areas combined with support in the first language. The second predictor is the use of interactive and communicative teaching/learning strategies and the teaching of language through content. The third predictor is the socio-cultural context of the school itself. Where the school staff were highly skilled, where the school curriculum was inclusive of minority students and their language and cultural backgrounds, and where the expectations of minority student achievement were high, that school achieved high student outcomes.

Rhamie (2007) identified factors that contributed to high academic achievement among African Caribbean background students in the United Kingdom. The following factors, among others, are found to be influential: school ethos and atmosphere that convey encouragement and motivation; teachers who are caring and encouraging, role models, active and consistent involvement in community activities; and parents who are welleducated and have high status occupations, thus being able to give children consistent and practical help besides verbal encouragement.

In Chinese contexts, the growing literature on minority education shows evidence of lower investment in minority education in China (Bass, 1998, Postiglione, 1992) compounded by inappropriate curricula and shortages of qualified language teachers (e.g. Postiglione, 2000; Postiglione et al., 2007; Tsung, 2009). Teachers have lower expectations of minority background children (Hansen, 1999; Kwong et al., 1989; Lee, 2001; White, 1998) and there is also resistance from minority groups to an education which is perceived to devalue and exclude culture, language and traditions (Hansen, 1999; Johnson and Chhetri, 2000; Zhou, 2000). Tsung (2009) found that a major factor in low outcomes was due, not to the type of school (separate bilingual or mixed), but to the lack of resourcing and support for minority students in general:

\section{South Asian Students in Focus}

SA background students have figured in much of the research from the United States and United Kingdom. In the United Kingdom children of SA backgrounds fall behind white children during primary school, and on entry to secondary school, they are achieving at a lower level even when socio-economic status is taken into account. Asian background students catch up during secondary school and obtain similar examination results to majority students (Maugham and Rutter, 1986; Smith and Tomlinson, 1989).
There are differences between different language/ethnic backgrounds with students of Pakistani and Bangladeshi backgrounds constantly having lower outcomes than students of Indian backgrounds (Haque and Bell, 2001).

This complex picture of educational outcomes is confirmed in US research. Portes and Zhou (1993) in studies of Punjabi Sikh and other communities found a 'segmented' picture of outcomes, with one pattern being upward mobility combined with loss of first language and culture, a second pattern being continuation of low outcomes between generations and the third being 'rapid economic advancement with deliberate preservation of the immigrant community's values and tight solidarity' (Portes and Zhou, 1993: 82).

In the educational setting of Hong Kong, research evidence shows that SA students have enormous difficulties in learning the Chinese language, and have limited education choices and opportunities since most of the public schools adopt Chinese as the medium of instruction (Ku et al., 2005; Loper, 2004). In addition, very few SA students have the opportunity of attending tertiary institutions because of the low quality of their school education and the lack of necessary Chinese language skills ( $\mathrm{Ku}$ et al., 2005). In one study, parents' worries about children 'studying Chinese subjects' rated highest on the list of parental concerns (Ting et al., 2007). Another study discovered that up to $77 \%$ of the Nepali parents thought that their children faced tremendous difficulties in learning the Chinese language, and $21 \%$ pointed out there was a shortage of tutorial support (Society for Community Organization, 2004).

The Chinese language classes provided for SA students have been reported as inappropriate and inadequate (e.g. ICESCR Second Report, 2003; Ku et al., 2005; Loper, 2004). Loper (2004) found that the written Chinese language classes are either unavailable to SA students, or, when available, are not suited to their individual needs and levels. Minority primary students generally have a Chinese vocabulary of less than one hundred where several thousand are required for basic reading (Hong Kong Unison, 2007). Minority students also report difficulties in communicating with Cantonese-speaking peers (Ku et al., 2005; Loper, 2004).

The Hong Kong government's continued efforts to improve the proficiency in Chinese language among ethnic minorities are reflected in its initiatives to allocate a recurrent annual allowance of $\mathrm{HK} \$ 300,000$ to the existing designated schools from the 2008-2009 school year (HKSAR government 2008), and to fund intervention programs/additional tutorial classes in Chinese for minority students. Government policy seems on the 
one hand to be attempting to 'integrate' minority students into mainstream schools without any specific provision in terms of their first language. On the other hand, it is making some short-term concessions in tertiary entry and support in designated schools. The question is how can the structural factors that cause disadvantage be best addressed and how can the language and educational needs of minority students be addressed: minority background students who have different home languages and who are second language learners of Cantonese, Putonghua and English. To what extent are designated schools (targeted provision) successful in providing access to the majority language and improving educational outcomes?

\section{Methodology}

This study adopted semi-structured interviews with teachers who teach CSL to SA students with SA parents as well to explore the educational experiences of SA students in school context and identify the factors that influence their educational attainment through the teaching/learning of Chinese. The in-depth interviews were undertaken with 31 Chinese language teachers from 5 designated schools and 26 parents of the SA students in these schools. The questions were designed so as to solicit informants' own views on Chinese language learning experiences of SA students and the factors they perceived as relating to these students' learning outcomes. Interview data were transcribed verbatim and informants' responses were grouped according to answers to specific interview questions. Major issues were identified by a content and thematic analysis and then transcripts were reanalysed to identify comments on these emerging themes and issues.

The five schools are situated in the east of Hong Kong Island, east and west of Kowloon, and northern part of the New Territory. All of them have substantial number of SA students, meaning that they have one or more classes of these students in each of the different levels of the schools. Two of the schools already took minority students in the 1980s and 1990s; others began taking these students in the early 2000 s, or only did so in the recent years when they had a drop in the number of local Chinese students.

The teacher interviewees showed great diversity in their background. Their experience in teaching SA students ranged from three weeks to seven years. Nine had teaching experience of five to seven years; twelve had been teaching Chinese for three to five years, mostly to mainstream students; seven had less than three years of teaching experience and had also taught mainstream students; and three were new teachers. Only two teachers received formal CSL training and were certified CSL teachers. The teachers (twenty females and eleven males) were all of Cantonese background.

Among the twenty-six parent informants, twenty-one had been residing in Hong Kong from seven to forty-two years and were already permanent residents. The others were new arrivals (from several months to one year) and those who had been living in the city for less than seven years. From the interview set, eight parents had university degrees, others had secondary (eight parents) or primary (ten parents) education. The fathers were in such occupations as security guards, construction workers, restaurant waiters or office clerks, while the mothers served as domestic helpers, secretaries and cleaners. They were comprised of five ethnic backgrounds: nine came from Nepal, seven from Pakistan, five from the Philippines, four from India and one from Vietnam.

\section{Findings}

\section{Teachers' readiness and efficacy in teaching SA students}

Thematic analysis of comments on teacher effectiveness and training indicated that teachers have realized that they had inadequate preparation, that there was inappropriate curriculum and that students were being taught and treated as if they were first language speakers of Chinese.

Teacher interviewees identified the lack of appropriate teacher training and professional development. They reported that the five schools were all having a difficult time in teaching the SA students due to a serious shortage of qualified and experienced CSL teachers. Many Chinese language teachers who have been teaching local students Chinese are appointed to teach SA students. Following are two typical responses of the teachers to the above concerns:

We appointed an English teacher when we first began [to teach SA students Chinese] ... The teacher was a major in Translation and proficient in both Chinese and English. The second teacher's specialty was also in Translation. As for training, we don't know how to train them and who can train them. They didn't have any training in teaching CSL. But teachers' teaching techniques are very important. (Teacher 2)

The training of [CSL] teachers, knowledge about teaching and learning strategies are very important. Teachers should know what makes effective teaching. But our teachers lack such knowledge. They don't have enough experience either. I think we need these most. Why do 
I say experience? Because if the teachers have no teaching experience in Chinese courses, they can hardly manage well and will experience much failure. (Teacher 30)

Teachers most frequently mentioned issues concerned with teaching characters. SA students tended to consider writing Chinese characters as a too difficult learning task and did not know how to make up the characters in the right way because they had no idea of components and strokes:

They [the SA students] are simply not able to 'draw' the characters that have many strokes. Therefore, at first, I taught them the components to give them some ideas of the structure of the characters. If they can understand, I will remind them of the appropriateness of the strokes when they are writing. In this way, I think they will develop an awareness of following the strokes while writing the Chinese characters. (Teacher 3 )

For many of the teachers, this was the first time they had encountered teenagers who did not understand characters and how to write them. In Chinese there is an accepted order in which to write the strokes in a character. Although SA students had difficulties in learning this order, none of the teachers questioned the appropriateness of their teaching of this order.

The respondents also talked about SA students' learning difficulties in speaking, vocabulary and composition. In the case of speaking, the difficulty lay in pronunciation and tones. Even with the help of Jyutping, a Romanized alphabet for standard Cantonese, the students still had difficulty in accurate pronunciation and tone. Teachers commented on students' inability to distinguish different characters with similar pronunciation. The difficulty in learning vocabulary was blamed on the lack of use of Chinese in daily life:

They cannot apply the words in real situations. For instance, I taught them the words '風扇' [fan]; I think they can use the words to say or write '我們 買了風扇' [we bought a fan], but they are not able to use the words in a sentence. They do not know when they can use the words. (Teacher 18)

SA students were also perceived as lacking the ability or being 'resistant' to memorizing. This was an interesting comment. It is natural for first language speakers to realize that memorizing of several thousand characters is needed for basic reading. Students used to alphabetic or syllabic scripts such as SA students would not have had this realization. The teachers in interviews tended to think that SA students were culturally different from Chinese students in that they are unaccustomed to rote learning and many of them dislike or even hate to memorize things when they are learning This leads to parents' perceptions of memorization and repetition when commenting on teaching methods.

\section{Teaching strategies and methods}

Eight SA parents $(30 \%)$ commented that their children found learning Chinese difficult and boring because teachers used ineffective teaching methods. Copying and repetition are the typical methods used by native Chinese-speaking learners, especially at the early stage of learning Chinese. However, both SA parents and students considered this to be boring and undesirable, and were to some degree resistant to such methods. For example, one Nepali mother said:

My daughters are asked to copy new characters many times. Sometimes, they say they cannot remember them although they copy many times. They say many characters look very similar, but they are different and have different meanings. It is difficult to tell the difference. And they often do not know which one to pick for use. (Parent 4)

SA students learn Chinese as a second or even third language. Appropriate teaching methods thus need to be developed to address their special needs. The biggest challenge is to teach them how to use Chinese appropriately in their daily lives. Otherwise, they will quickly forget what they have learned in class without ever putting it into use.

Since English is the stronger language for most of the SA students, parents suggested that Chinese language teachers should utilize English when teaching grammar. This would help students understand the grammatical concepts of Chinese more quickly and effectively. In other words, English can definitely be used as a tool to help SA students develop a feel for Chinese.

Interestingly, ten parents (38\%) expressed a desire for their children to be taught Chinese grammar systematically from the beginning of their study. They felt that schools emphasized practical everyday Chinese while the importance of formal grammar was compromised. Although the students were able to use what they had practiced in school, they were unable to 
employ this in creating new sentences and texts. One father who had foreign language learning experience remarked:

Grammar is very important for learning Chinese, for learning any foreign language, I think. Good grammar can help students understand how to form a sentence and then a paragraph of text. If the teachers teach good grammar, the students will improve a lot in writing. This is because they know how to use what they have been taught in class to form sentences to express their ideas. (Parent 7)

These parental responses could have indicated different attitudes. It could mean parents wanting schools to focus more on the formal language and therefore their children's opportunities for further study. It could also have reflected the parents' own experiences in language learning. It may also have been an indication that teachers did not see the teaching of grammar as possible or appropriate for these students. These comments on overemphasis on repetition and the lack of grammatical explanations reflect the findings of Bell (1995) who carried out an auto-ethnographic study of her own learning of Chinese in Hong Kong as a non-native speaker. Whatever the reasons, it is important that parents' comments are explored further and taken seriously. The teachers need to be aware of the negative effects of their overreliance on repetition which could restrict the ability of SA students from fully expressing themselves in Chinese. Schools and teachers also need to explore recent approaches to the teaching of more formal aspects of the language.

\section{Learning motivation}

The issue of motivation emerged as a common issue with most of the teacher interviewees. Teachers viewed most SA background students as not sufficiently motivated to learn the Chinese language well for several reasons. First, teachers perceived an indifference to the Chinese language and believed SA students brought predetermined negative attitudes to the Chinese language classroom. A typical comment echoed by a majority of teachers was:

Many minority students do not attach much importance to the learning of Chinese. Some of them have been living in Hong Kong since they were born and they have completed primary education in Hong Kong, but they still cannot speak the language. They seem to ignore the language. (Teacher 11)

In other words, teachers did not see the negative attitudes to Chinese constructed in the classroom or schools, but as something which students brought with them from the community. There was an element of blame attached to students' lack of proficiency in Chinese.

Second, teachers believed that most SA background students felt that Chinese is a difficult language to learn, especially in terms of writing.

Most Form 1 students actually do not want to learn Chinese, but their parents think they do, and we teachers also think they wish to learn. In fact, I find them experiencing enormous difficulties and bitterness in learning. They learn the language unwillingly . . . They feel the Chinese courses are too difficult and boring. (Teacher 7)

In most cases, their reporting of student perceptions did not go with an understanding of the difficulties students faced. Students were compared with local students whom they felt would not baulk at the challenge of difficult work.

Third, there were comments constructing the SA communities as insular and segregated and reluctant to integrate with majority group/s. A comment typical of many was:

They [SA students] tend to live in their own circle of life and have little chance to use what they have learnt in Chinese courses in daily life. (Teacher 12)

Many teachers also noted that students were motivated to acquire the local spoken language, Cantonese, as this was deemed more relevant to daily life and future career. The negative attitudes were more directed towards written Chinese.

The students are obviously more active in learning how to speak the language. They want to acquire some simple conversational Cantonese so that they can communicate with Chinese students ... They are also happy when they participate in speaking activities. However, they are reluctant to learn the characters because they think that they have no such need. (Teacher 22) 
While the teachers generally considered SA students as unmotivated learners of Chinese, all the parents claimed that they and their children had recognized the increasing importance of Chinese in today's Hong Kong and for their children's future education and job opportunities, as one parent said:

Our children have to learn Chinese. Their future is in Hong Kong, so they have to learn Chinese. Yea ... in future if they want to join for working somewhere, then they need to learn Chinese of course. (Parent 23)

In principle, if an individual has developed an awareness of need for learning, he or she will be motivated by the need to learn. However, even the positive comments from the teachers about students wanting to learn spoken Cantonese indicated negative perceptions of students. The students were characterized as operating only for instrumental motivation: to communicate in daily life or for future low-skilled careers outside school.

\section{Educational experiences in school}

The socio-cultural context of the schools was not considered by the parent informants as sufficiently supportive and inclusive of SA linguistic and cultural backgrounds/capital. Seven parents (27\%) claimed that their children had unpleasant experiences at school. One complaint was that local teachers tended to regard SA children as slow learners, thereby underestimating their learning potential. One Pakistani father made the following comment:

My daughter told me that their teachers think minority students are not as clever as the local students and they cannot possibly be good students. She feels the teachers treat minority students differently from others. (Parent 13)

One Nepali parent made a similar complaint:

When a minority student does something wrong, the teacher will punish him seriously. But if this happens to a Hong Kong student, the teacher maybe ignores the incident and lets him go. (Parent 17)

The bias of many Hong Kong teachers against minority students may impose more pressure on the latter. It is more likely that any unfair treatment will exacerbate the difficulties that minority students face. Invariably, they would have to work much harder than local students simply to be thought of as good students.

In addition, SA students seemed to be isolated from the majority of local Chinese-speaking students. Mutual understanding between these groups appeared hard to achieve. According to the parents, their children felt that establishing friendships with local Chinese students was quite difficult. In fact, their children only developed friendships with students from other ethnic minority groups. It was likely that the language barrier was one major reason. One Filipino mother said in interview:

They do not know each other's language well, so they cannot understand each other very well. And so they cannot make good friends. (Parent 21)

Furthermore, given that many SA students have poor pronunciation in Cantonese, some of their local schoolmates make fun of them. The parents felt that such ridicule discouraged their children and they no longer dared to speak the language. Hence, the parents suggested that schools should work out some solutions to improve the relationships between minority and local students for the two parties to support each other in learning.

Another problem is the lack of encouragement. SA students, particularly the new arrivals, confront great difficulties in learning and will need consistent encouragement from teachers and classmates. However, one third of the parents complained that local teachers were neither encouraging nor sufficiently patient when it came to teaching their children. According to them, most teachers failed to help minority students build self-confidence and develop effective approaches to learning. They believed that given more care and encouragement, their children would be more successful learners.

There was also a lack of appreciation of SA linguistic capital. SA students in designated schools learn Chinese as a subject and are taught other subjects through English. During the course of their schooling, their mother tongue is seriously lacked. One Pakistani parent remarked:

Of course, it [Urdu] is their [the children's] mother language, so they understand well. They will understand this, you know, the instruction. So for the English, English is also the second language for them, not the mother language. And although, there are only few lucky children, their parents are educated and their mothers are educated, because, we the 
Pakistanis, some mothers even don't know ABCD and parents can't help their kids. (Parent 25)

Although SA home languages, such as Hindi, Nepali, Urdu and Punjabi, are taught in a few schools as elective subjects there seems to be no systematic provision. Many studies indicate, however, that the most effective pathway to literacy in any language is through the language that children are strongest in (Verhoeven, 1991).

\section{Discussion and Conclusions}

Teachers' lack of experiences and efficacy in teaching CSL and in communicating with SA students indicate that Chinese subject teachers in Hong Kong secondary schools have not been adequately prepared to teach children from cultural and linguistic backgrounds different from their own. There has been a research focus by scholars on teacher experience and effectiveness that account for the varied outcomes in second language learning. Teachers' experience has consequences which are characterized by the attention to multicultural understanding and awareness of cultural issues when teaching their culturally diverse students, and also by the self-efficacy of skills and knowledge in second language teaching (CochranSmith and Lytle, 1993; Lee, 2006). The shortage of self-efficacy of skills and knowledge about teaching in the environment of a multicultural classroom frequently leads to the incompetence of teachers in designing and organizing second language teaching.

Interview findings indicated that many teachers were using teaching methods similar to those for native Chinese speakers and not appropriate for students learning CSL. Tsung et al. (2008) found that $24 \%$ of students considered the Chinese lessons as boring or not useful. This presents a need for innovative and productive pedagogy for SA students. The specific learning needs and characteristics of SA students should be the major considerations taken into account in developing such pedagogy. This relates to the issue of CSL teacher training.

Interview responses clearly identified the need for appropriate professional development and the need for teachers to gain in-service and preservice training in teaching CSL. There is no strict requirement for teachers to have qualifications in teaching CSL in designated schools and there are few avenues for teachers to gain such qualifications. Currently there is one central Chinese language curriculum for all students irrespective of their language background. Only some supplementary guidelines are provided for schools to make adaptations of the curriculum to suit the needs of SA students. This leaves most of the challenges in teaching SA students to the classroom teachers. Without professional development and support, teachers would find these challenges too demanding.

One study reported that only $42 \%$ of SA students wanted to learn Chinese at school; the most important reasons for learning Chinese included: 'to get a job' (48\%), 'to pass an examination' (39\%), 'to make friends' (34\%), and 'my parents want me to learn' (29\%) (Tsung et al., 2008). As indicated in the interview responses in this study, SA students were more motivated to practice spoken Cantonese than learning Chinese characters, and parents expected their children to gain Chinese fluency only for a good job. This reflects SA community's more utilitarian orientation to learning Chinese in order to accomplish some immediate goals such as to pass an exam or to advance a career. Such orientation is identified by Gardner (1985) and others (Cookes and Schmidt, 1991; Hudson, 2000) as instrumental motivation, in contrast with integrative motivation for the purpose of learning more about the cultural community of the target language or increasing the affiliation with the target community. Evidently, integrative motivation for the acceptance and integration into Hong Kong mainstream society lacked among the SA students.

Debates around minority student education often focus on the organization and structure of the schooling: should students be integrated in mainstream classes or should they be provided with separate/targeted schooling? It is beyond the focus of this study to discuss which type of provision is more effective. Yet, the SA students in designated schools being placed in a separate stream where they are taught through English and have Chinese only as one of their subjects means that there is no teaching through content areas and the access to learning Chinese is limited. The teaching of Chinese is clearly inadequate for these students.

With regard to the context of the schools, interview data indicated teachers' low skills in communicating with minority students; schools' inadequate initiatives to promote mutual understanding and collaborative learning between minority and local students; teachers' lowered expectations of student performance; and exclusion of SA linguistic background. There were also few teachers of SA background in the school system and there was no evidence of any employment policy to place these teachers where they were most needed. Usually the native languages of SA ethnic minorities are not encouraged, and the schools have no resources to provide systematic teaching of these languages or provide school subjects teaching 
through these languages. In principle, this appears to contradict Hong Kong's language policy which states that students will learn more efficiently and achieve better results in their mother tongue. Ideally, the large SA communities could be provided with mother tongue instruction, or at least the chance to study some school subjects in their native languages.

School education in Hong Kong for its immigrants and minorities has great economic and socio-political importance. The informants' perspectives on the deficiencies in school provision and support, the less desirable school environment for SA students and their lack of integrative learning motivation indicate the complexity of educational provision for SA students and the slim chances for these students to achieve academic success. The current approach to teaching is still that of first not second language teaching. Curriculum and pedagogy development, and teacher training are all clearly inadequate. Although the government has provided extensive support, the effectiveness of the support is limited if there is no coordination between schools, educators, the CSL curriculum developers and CSL teacher trainers. The policy should then be directed both at creating a suitable CSL curriculum to be taught by trained CSL teachers and at encouraging SA students to gain fluency and literacy in Chinese as a gateway to a full advantage of the political, social, educational and economic opportunities guaranteed to all citizens.

\section{References}

Bass, C. (1998), Education in Tibet: Policy and Practice since 1950. London: Zed Books.

Bell, J. (1995), 'The relationship between L1 and L2 literacy: Some complicating factors', TESOL Quarterly, 29, (4), 687-704.

Census and Statistics Department (2007), Thematic report of Hong Kong 2006 population by-census: Ethnic minorities, viewed 19 March 2008, http://www.bycensus2006. gov.hk/en/data/data2/index.htm

Cochran-Smith, M. and Lytle, S. (1993), Inside/Outside: Teacher Research and Knowledge. New York: Teachers College Press.

Cookes, G. and Schmidt, R. W. (1991), 'Motivation: Reopening the research agenda', Language Learning, 41, (4), 469-512.

Crul, M. and Vermeulen, H. (2003), 'The second generation in Europe', International Migration Review, 37, (4), 965-986.

Gardner, R. C. (1985), Social Psychology and Second Language Learning: The Role of Attitudes and Motivation. London: Edward Arnold.

Hansen, M. H. (1999), Lessons in Being Chinese: Minority Education and Ethnic Identity in Southwest China. Seattle: University of Washington Press.
Haque, Z. and Bell, J. (2001), 'Evaluating the performance of minority ethnic pupils in secondary schools', Oxford Review of Education, 27, (3), 359-368.

HKSAR Government (2008), The 2008-09 budget, viewed 20 March 2008, http:// www.budget.gov.hk/2008/eng/budget60.html

Hong Kong Unison (2007), Submission to the Panel on Education meeting on Monday, 8 January 2007, LC Paper No. CB(2) 804/06-07(01)

Hudson, G. (2000), Essential Introductory Linguistics. Malden: Blackwell Publishers.

ICESCR Second Report (2003), Second Report of the Hong Kong Special Administrative Region of the People's Republic of China in the Light of the International Covenant on Economic, Social and Cultural Rights, paras 13-24, Hong Kong, HKSAR Government.

Johnson, B. and Chhetri, N. (2000), 'Exclusionary policies and practices in Chinese minority education: A case of Tibetan education', Current Issues in Comparative Education, 2, (2), 1-13.

$\mathrm{Ku}, \mathrm{H}$. B., Chan, K. W. and Sandhu, K. K. (2005), A Research Report on the Education of South Asian Ethnic Minority Groups in Hong Kong (2nd edition). Hong Kong: Centre for Social Policy Studies, Department of Applied Social Sciences, the Hong Kong Polytechnic University, and Unison Hong Kong.

Kwong, J. and Xiao, H. (1989), 'Educational equality among China's minorities', Comparative Education, 25, (2), 229-243.

Lee, M. B. (2001), Ethnicity, Education and Empotverment: How Minority Students in Southwest China Construct Identities. Aldershot: Ashgate Publishing Limited.

Lee, M. S. (2006), 'Becoming multilingual: A study of South Asian students in a Hong Kong secondary school.' Master dissertation, University of Hong Kong.

Loper, K. (2004), Race and Equality: A Study of Ethnic Minorities in Hong Kong's Education System. Hong Kong: Centre for Comparative and Public Law, Faculty of Law, the University of Hong Kong.

Maugham, T. and Rutter, M. (1986), 'Black pupils' progress in secondary schools. II Educational attainments', British Developmental Psychology, 4, 19-29.

PISA (Programme for International Student Assessment) (2004), Learning for tomorrow's world: First results from PISA 2003, viewed 30 October 2006, from OECD website: http://www.pisa.oecd.org

PISA (Programme for International Student Assessment) (2006), Where immigrant students succeed: A comparative review of performance and engagement in PISA 2003, viewed 12 October 2006, OECD website: http://www.pisa.oecd.org

Portes, A. and Rumbaut, R. (2001), Legacies: The Story of Immigrant Second Generation. Berkeley: University of California Press.

Portes, A. and Zhou, M. (1993), 'The new second generation: Segmented assimilation and its variants among post-1995 immigrant youth', Annals of the American Academy of Political and Social Science, 530, 74-98.

Postiglione, G. A. (1992), 'The implications of modernization for the education of China's national minorities', in R. Hayhoe (ed.), Education and Modernization: The Chinese Experience. Oxford: Pergamon Press, pp. 307-336.

Postiglione, G. A. (2000), 'National minority regions: Studying school discontinuation', in J. Liu, H. A. Ross and D. P. Kelly (eds), The Ethnographic Eye: Interpretive Studies of Education in China. New York: Falmer Press, pp. 51-72. 
Postiglione, G. A., Jiao, B. and Manlaji (2007), 'Language in Tibetan education: The case of the Neidiban', in A. Feng (ed.), Bilingual Education in China: Practices, Policies and Concepts. New York: Multilingual Matters, pp. 49-71.

Rhamie, J. (2007), Eagles Who Soar: How Black Learners Find the Path to Success. Stoke on Trent, UK: Trentham Books.

Smith, D. and Tomlinson, S. (1989), The School Effect: A Study of Multi-Racial Comprehensives, London: Policy Studies Institute.

Society for Community Organization (2004), A Study of the Nepalese Community in Hong Kong. Hong Kong, Movement Against Discrimination.

Thomas, W. P. and Collier, V. (1997), School Effectiveness for Language Minority Students. Washington, DC: National Clearinghouse for Bilingual Education.

Thomson, M. and Crul, M. (2007), 'The second generation in Europe and the United States: How is the transatlantic debate relevant for further research on the European second generation?' Journal of Ethnic and Migration Studies, 33, (7), 1023-1041

Ting, W. F., Liu, S. C., Chan, W. K. Chan, C. H. and Chak, T. C. (2007), A Research Report on the Social Situations of Ethnic Minority Women in Hong Kong. Hong Kong, Department of Applied Social Sciences, the Hong Kong Polytechnic University, and Project South Asians Support Alliance, Hong Kong Christian Service.

Tsung, L. (2009), Minority Languages, Education and Communities in China. New York: Palgrave Macmillan.

Tsung, T. H., Shum, M. S. K. and Ki, W. W. (2008), 'Language situation of South Asian students in Hong Kong', in Language Situation in China: 2007. Beijing: Commercial Press.

Verhoeven, L. (1991), 'Acquisition of biliteracy', AILA Review, 8, 61-74.

White, S. D. (1998), 'State discourses, minority policies, and the politics of identity in the Lijiang Naxi People's Autonomous County', in W. Safran (ed.), Nationalism and Ethnoregional Identities in China. Portland, OR: Frank Cass.

Zhou, M. (2000), 'Language policy and illiteracy in ethnic minority communities in China', Journal of Multilingual and Multicultural Development, 21, (2), 129-148.

\section{Chapter 6}

\section{Bilingual Education and Korean Minorities in China}

\author{
Fang Gao
}

\section{Introduction: Learning CSL in China}

This chapter documents the motivations and strategies of learning CSL among ethnic Koreans in Northeast China. Both the integrative motivation and instrumental motivation, and the main strategies in establishing intercultural contexts both inside and outside school for Chinese language acquisition are described.

Second language acquisition has long been a common activity for a majority of the world's population and is becoming even more vital as second languages increase in importance (Cummins, 1988; Thomas and Collier, 1997). Modern states are expected to provide education to the children of immigrants and other language minority children; in most cases, the intention is that these children are integrated with the children of the majority, both as a goal and as a means to reach the goal of schooling for integration into the mainstream. This is particularly true for China. China has $\mathbf{5 5}$ officially recognized 'minority nationalities' (shaoshu minzu), which account for about $9.44 \%$ of the total population (NBSC, 2005). In comparison with the motivations for those studying CSL in non-Chinese speaking countries (duiwai hanyu jiaoxue) such as in North America, Europe and African countries, learning CSL (Putonghua) in China for minorities has strong economic and socio-political importance (Feng, 2007). The increasing significance of Chinese language in the market economy since the end of 1970s has led to the emphasis on Chinese language studies in state schooling for the integration of ethnic minorities into the mainstream economy (Postiglione, 1999). Bilingual education (Chinese and minority language) began to be implemented in the mid-1980s as a transitional 